\title{
Research Article \\ Performance of BFRP Retrofitted RCC Piles Subjected to Axial Loads
}

\author{
Anandakumar Ramaswamy, ${ }^{1}$ Selvamony Chachithanantham, ${ }^{2}$ and Seeni Arumugam ${ }^{3}$ \\ ${ }^{1}$ Anna University, Chennai, Tamil Nadu, India \\ ${ }^{2}$ Department of Civil Engineering, Sun College of Engineering \& Technology, Tamil Nadu, India \\ ${ }^{3}$ Department of Civil Engineering, S. V.C. College of Engineering \& Technology, Tamil Nadu, India
}

Correspondence should be addressed to Anandakumar Ramaswamy; anandakumar.mtech@gmail.com

Received 1 August 2014; Revised 20 September 2014; Accepted 21 September 2014; Published 19 October 2014

Academic Editor: Dachamir Hotza

Copyright (C) 2014 Anandakumar Ramaswamy et al. This is an open access article distributed under the Creative Commons Attribution License, which permits unrestricted use, distribution, and reproduction in any medium, provided the original work is properly cited.

\begin{abstract}
This paper deals with the behaviour of basalt fibre reinforced polymer (BFRP) composites retrofitted RCC piles subjected to axial compression loads. Currently the awareness of using FRP increases rapidly in engineering fields and also among public. Retrofitting becomes vital for aged and damaged concrete structures, piles, and so forth, to improve its load carrying capacity and to extend the service life. The load carrying capacity of piles retrofitted with basalt unidirectional fabric was studied experimentally. 15 nos. of RCC end bearing pile elements were cast with same reinforcement for axial compression experiment. Three piles were used as conventional elements, another 3 piles were used as double BFRP wrapped pile elements, and remaining 9 piles were used as retrofitted piles with BFRP double wrapping after preloaded to $30 \%, 60 \%$, and $90 \%$ of ultimate load of conventional element. The effects of retrofitting of RCC pile elements were observed and a mathematical prediction was developed for calculation of retrofitting strength. The stress vs. strain relationship curve, load vs. deformation curve, preloaded elements strength losses are tabulated and plotted. Besides, crack patterns of conventional elements and tearing BFRP wrapped elements were also observed. The BFRP wrapped elements and retrofitted elements withstand more axial compressive load than the conventional elements.
\end{abstract}

\section{Introduction}

Generally the RCC structures are degrading due to corrosion, multiple environmental effects, poor quality of construction, deterioration and damages, age, fatigue, increment of live loads, and so forth. Particularly RCC pile foundation shafts and caps are frequently affected and damaged by any one of the above causes. These structures can be strengthened or retrofitted by using the best suited method from jacketing, overlaying, stitching, grouting, sealing, coating, NSM systems, FRP wrapping, rebaring, blanketing, and so forth. FRP wrapping system is well suited for rapid retrofitting works without the application of heavy tools and skilled labours. It won good characteristics such as high chemical and heat resistance, low fatigue loss, high flexibility, high tensile strength, light weight, high impermeability and corrosion free because it is non metallic. Hence, the FRP wrapping method was chosen for this experiment by using basalt unidirectional fabric. The aim of the research study is to assess the behaviour and performance of retrofitted pile elements subjected to axial compression load, impact load, lateral load, and skin friction. This paper mainly focuses on the behaviour of BFRP wrapped piles under the axial compression load. For this study, it is considered the slender piles only, because the piles are slender members, that is, the ratio between effective length and least lateral dimension is greater than 12 . As, the load carrying capacity of slender piles are less than that of short piles and various properties like flexural buckling, torsional buckling, strain, and so forth are very much less, when compared to the short piles. The slender piles are considered for this research study. In relation to that, some research articles were reviewed for this experiment and expressed.

Purushotham Reddy et al. experimented RCC piles that is strengthened with GFRP composites under various loading conditions and compared the experimental results with analytical results obtained using ANSYS. They observed that 
the load carrying capacity of the elements retrofitted with GFRP is found to be greater than that of the control elements for ultimate axial compression and lateral loads at various levels [1].

Olivova and Bilcik evaluated the performance of near surface mounted (NSM) laminates with CFRP wrapped columns using both experimental and analytical methods. The adoption of the NSM technique by using precut grooves in concrete cover resulted in significant increase of load carrying capacity of columns subjected to bending. Some of the experimental researches were carried for specimens under cyclic loadings and seismic loading. However, most of the researches show the performance of specimens under static axial loads and static lateral loads [2].

Abbasnia and Holakoo presented the stress-strain behaviour of CFRP confined concrete under monotonic and cyclic compression. They found that the existing models such as Shao model and Lam and Teng model have less accuracy in predicting the stress, strain, and unloading path [3].

The effects of cyclic loading and the behaviour of the confined concrete in hybrid DSTCs (hybrid FRP-concrete-steel double skin tubular columns) under cyclic axial compression were studied by $\mathrm{Yu}$ et al. It was found that the repeated unloading and reloading cycles result in cumulative effects on the permanent stress and strain deterioration of the confined concrete [4].

Desprez and Mazars presented a new simplified modeling strategy for reproducing the nonlinear cyclic behaviour of FRP retrofitted RC columns. This can serve as a numerical tool for quick comparative studies on various confinement situations and structure vulnerability before and after FRP retrofitting [5].

Ozbakkaloglu and Louk Fanggi conducted experimental study on the behaviour of FRP-HSC steel composite columns subjected to monotonic and cyclic axial compression. They made experiment investigation on the double-skin tubular columns and elaborated that the compression behaviour is governed by the concrete strength, steel tube diameter, loading pattern, thickness, and end conditions [6]. Ferracuti and Savoia introduced cyclic constitutive laws for confined and unconfined concrete under compression and concrete under tension and also the steel reinforcing bars. The effects of the axial loads on the damping factor were studied [7].

The strengthening configuration of columns subjected to combined axial load simulating gravity load and reverse cyclic lateral load simulating earth quake load were applied by Sadone et al. on CFRP confined columns with bonded longitudinal CFRP plates [8].

Mirmiran et al. conducted their paper that field experiments have shown concrete filled tubes to be a feasible alternative for bridge substructures. The driving stresses in filled tubes were comparable to those for prestressed concrete piles. Empty tubes may buckle or rupture under driving impact, unless driven at shallow depths and in soft soil or with a steel mandrel. The parametric study using the wave equation further confirmed that there is no difference in the drivability of filled FRP tubes and prestressed concrete piles of the same cross sectional area and concrete strength [9].
Fam et al. detailed that the construction and driving of piles, comparisons between the behaviour of the composite (circular cross section) and prestressed concrete piles (square cross section) under axial and lateral loading, the absorbed failure modes, and the details of connection between the piles and the reinforced concrete cap. The use of concrete filled GFRP tubes as piling for bridge piers is practical and feasible. Both the composite and prestressed concrete piles performed similarly under the axial load test and also the failure due to axial load was significantly higher than the design pile load. In addition, the lateral load field test on both the composite and prestressed piles showed similar behaviour to that attained from the laboratory flexural test and analysis [10].

Parvin and Brighton showed the collective usage of FRP in strengthening columns under several loading exposures. Although, there are numerous amount of FRP strengthening techniques, the BFRP composites wrapping proves to be one of the best retrofitting method [11]. The current study deals with the determination of behaviour and performance of BFRP composites wrapped piles subjected to axial load.

\section{Objectives}

The main objectives of this paper are

(i) to retrofit the pile grade loss elements by using basalt fibre,

(ii) to find out the compressive strength, split tensile strength and flexural strength of BFRP retrofitted specimens in single and double wrapping,

(iii) to study the performance of BFRP double wrapped single end bearing RCC piles under axial loading,

(iv) to determine the stress versus strain, load versus deformation behaviours, cracks patterns and to compare with conventional pile elements,

(v) to determine the strength of retrofitted elements,

(vi) to compare the load carrying capacity of conventional pile specimen and retrofitted pile specimen based on IS 2911-Part 1/Sec 3-1984.

\section{Materials and Methods}

3.1. Experiment Test Materials. For this experiment, the following ingredient such as 43 grade OPC cement, fine aggregate, coarse aggregate, water, steel, basalt unidirectional fabric, and epoxy were used for specimens like cube, cylinder and prism, and end bearing RCC pile element casting and retrofitting purposes.

The ingredients were tested as per Indian standard codes for finding out the properties. Cement was tested as per IS 8112-1989, aggregates were tested as per IS 383-1970, and steel testing was made as per IS 1786-1985. After testing the ingredient properties were obtained and tabulated under Tables 1, 2, and 3.

The basalt fibre properties are got from the M/S Zhe Jiang, GBF Basalt Fibre Co., Ltd., China data sheet. Which are obtained in Table 4. 
TABle 1: Properties of cement.

\begin{tabular}{lc}
\hline Test conducted & Result \\
\hline Specific gravity & 3.15 \\
Fineness (specific surface) in $\mathrm{m}^{2} / \mathrm{kg}$ & 227.8 \\
Initial setting time in minute & 45 \\
Final setting time in minute & 585 \\
Standard consistency in \% & 36 \\
\hline
\end{tabular}

TABle 2: Properties of fine aggregate.

\begin{tabular}{lc}
\hline Test conducted & Result \\
\hline Specific gravity & 2.8 \\
Fineness modulus & 3.1 \\
Water absorption in \% & 0.5 \\
Surface texture & Smooth \\
Particle shape & Angular \\
\hline
\end{tabular}

TABle 3: Properties of coarse aggregate.

\begin{tabular}{lc}
\hline Test conducted & Result \\
\hline Specific gravity & 2.8 \\
Fineness modulus & 7.5 \\
Water absorption in \% & 0.5 \\
Surface texture & Smooth \\
Particle shape & Angular \\
Impact value in \% & 15.2 \\
Crushing value in \% & 18.6 \\
\hline
\end{tabular}

In this research the RCC piles are wrapped with basalt fibre by using the matrix of epoxy resin (Araldite LY 556) and hardener (Aradur 5021) in the ratio of $1: 0.15$. The epoxy resin and hardeners properties are got from Araldite company data sheet; it is noted in Table 5 .

Based on the ingredient test results it has been decided to design the $M_{30}$ grade concrete mix as IS $10262-2000$ for specimens and elements casting and testing for this experiment.

3.2. Experimental Test. Initially the concrete characteristic strengths were observed from conventional concrete specimens such as cubes, cylinders, and prisms as recommended in IS 516-1959. The experimental results and characteristics are noted in Table 6.

Nine specimens were wrapped with basalt unidirectional fabric by using epoxy composites in single layer and another 9 specimens were wrapped in double layer. During wrapping the orientation of fibre warp playing an important role in load carrying capacity. For this experiment the fibre warps are made along the circumference (hoop tension direction) for compressive strength, it shows in Figure 1. It proves to be effective when the overlapping of fibre wrapping is more than $25 \%$ of the specimen circumference. Figure 2 shows the orientation of fibre for flexural and tension strength warp is made along the vertical direction.

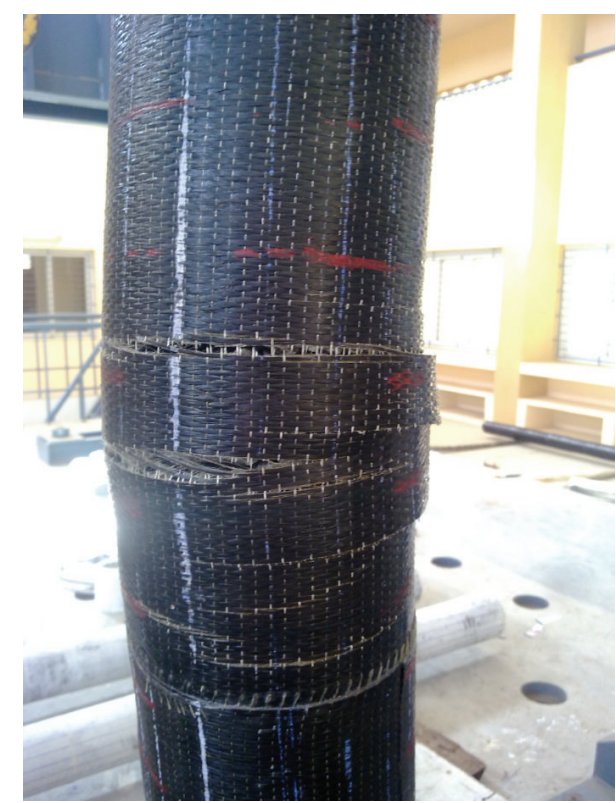

FIGURE 1: Orientation of fibre for compression warp in horizontal direction.

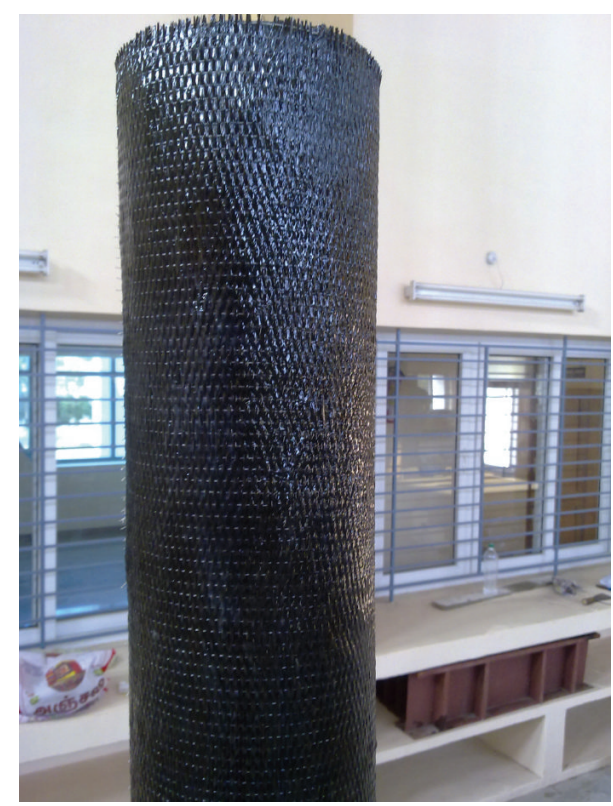

Figure 2: Orientation of fibre for flexural and tension warp in vertical direction.

For retrofitting experiment purposes, the 3 conventional specimens were preloaded to $30 \%$ of mean ultimate compressive strength of conventional specimens. Similarly, another 6 specimens were preloaded to $60 \%$ and $90 \%$ of ultimate load on each 3 specimens. These preloaded specimens are retrofitted with BFRP single wrapping for determining its retrofitting performance. Similarly moreover, another 9 nos. of cubes were preloaded and retrofitted with BFRP double wrapped for the same. 
TABLE 4: Basalt unidirectional fabric specifications.

\begin{tabular}{lccccc}
\hline $\begin{array}{l}\text { Basalt fabric } \\
\text { code }\end{array}$ & Structure weaving & Weight $\left(\mathrm{g} / \mathrm{m}^{2}\right)$ & Thickness $(\mathrm{mm})$ & Width $(\mathrm{mm})$ & \multicolumn{2}{c}{ Weft and warp density Ends/10 mm } \\
Warp & & Weft & 3.5 & 0 \\
\hline BWUD-450 & Unidirection (UD) & 450 & 0.36 & 600 & 3.5 \\
\hline
\end{tabular}

TABLE 5: Key data for Epoxy-Araldite LY 556 (resin).

\begin{tabular}{lcc}
\hline Description & Araldite LY 556 (resin) & Aradur 5021 (hardener paste) \\
\hline Aspect (visual) & Clear, pale yellow liquid & White viscous paste \\
Viscosity at $25^{\circ} \mathrm{C}($ ISO $9371 \mathrm{~B})$ & $10000-12000[\mathrm{mPa} \mathrm{s}]$ & $70000-90000[\mathrm{mPa} \mathrm{s}]$ \\
Density at $25^{\circ} \mathrm{C}(\mathrm{ISO} 1675)$ & $1.15-1.2\left[\mathrm{~g} / \mathrm{cm}^{3}\right]$ & $1\left[\mathrm{~g} / \mathrm{cm}^{3}\right]$ \\
\hline
\end{tabular}

TABLE 6: Conventional specimen's characteristics.

\begin{tabular}{|c|c|c|c|c|c|c|c|}
\hline \multirow{2}{*}{$\begin{array}{l}\text { Conventional } \\
\text { concrete } \\
\text { specimen }\end{array}$} & \multirow[b]{2}{*}{ Geometry in $\mathrm{mm}$} & \multicolumn{2}{|c|}{ Ultimate compressive strength } & \multicolumn{2}{|c|}{ Ultimate split tensile strength } & \multicolumn{2}{|c|}{ Ultimate flexural strength } \\
\hline & & Load in $\mathrm{kN}$ & $\begin{array}{l}\text { Stress in } \\
\mathrm{N} / \mathrm{mm}^{2}\end{array}$ & Load in $\mathrm{kN}$ & $\begin{array}{l}\text { Stress in } \\
\mathrm{N} / \mathrm{mm}^{2}\end{array}$ & Load in $\mathrm{kN}$ & $\begin{array}{l}\text { Stress in } \\
\mathrm{N} / \mathrm{mm}^{2}\end{array}$ \\
\hline Cube & $150 \times 150 \times 150$ & 803 & 35.7 & $\cdots$ & $\ldots$ & $\cdots$ & $\ldots$ \\
\hline Cylinder & $150 \varnothing \& 300$ length & $\cdots$ & $\cdots$ & 280 & 3.97 & $\cdots$ & $\cdots$ \\
\hline Prism & $\begin{array}{c}100 \times 100 \times 500 \\
\text { length }\end{array}$ & $\cdots$ & $\ldots$ & $\ldots$ & $\cdots$ & 10.80 & 5.4 \\
\hline
\end{tabular}

Double wrapped specimens showed more strength than conventional specimens and single wrapped specimens as shown in Figure 3. This is due to the high hoop tensile strength of double wrapped specimens than the single wrapped specimens and conventional specimens. Based on this results further experiments were made on double BFRP wrapping systems as the double wrapping specimens possess high compressive strength, split tensile strength and flexural strength than conventional and single wrapping specimens.

From the experiment results the mechanical properties were observed, analysed and plotted. A mathematical prediction equation was arrived for the compressive strength determination of retrofitted cube specimens.

3.2.1. Determination of Constants $C_{c}, k_{1}$, and $R_{c}$ for Compression Stress Cube. The following data were observed form this experiment.

Grade of concrete mix is $M_{30}$, characteristics compressive stress is

$$
f_{c k}=30 \mathrm{~N} / \mathrm{mm}^{2} \text {. }
$$

Experimental concrete cube characteristics compressive stress $f_{c k e}$ is

$$
f_{c k e}=k_{1} f_{c k}
$$

where $k_{1}$ is a constant and its value is arrived as 1.19 for all design calculation.

Characteristics compressive stress $f_{\text {ckw }}$ of BFRP double wrapped concrete cube is

$$
f_{c k w}=f_{c k e C_{c}},
$$

where $C_{c}$ is a constant and whose value is arrived as 1.5 for all design calculation.
Retrofitted Cubes. Retrofitted concrete cube strength is

$$
\begin{gathered}
f_{c k r}=f_{c k w R_{c}}, \\
f_{c k r}=k_{1} f_{c k C_{c} R_{c}} .
\end{gathered}
$$

BFRP double wrapped cube specimens preloaded by strength $30 \%$ of the compressive strength of conventional cube is calculated from constants as follows:

$$
f_{c k r}=f_{c k w R_{c}} \quad \text { or } \quad f_{c k r}=k_{1} f_{c k C_{c} R_{c}}
$$

$R_{c}$ value is taken as 0.994 from graph shown in Figure 4 .

Ultimate stress of retrofitted specimens

$$
\begin{aligned}
& =1.19 \times 30 \times 1.5 \times 0.994 \\
& =53.22 \mathrm{~N} / \mathrm{mm}^{2}
\end{aligned}
$$

BFRP double wrapped cube specimens preloaded by strength $60 \%$ of the compressive strength of conventional cube is calculated from constants as follows:

$$
f_{c k r}=f_{c k w R}
$$

or

$$
f_{c k r}=k_{1} f_{c k C_{c} R_{c}} \text {. }
$$

$R_{c}$ value is taken as 0.98 from graph shown in Figure 4. Consider

Ultimate stress of retrofitted specimens

$$
\begin{aligned}
& =1.19 \times 30 \times 1.5 \times 0.98 \\
& =52.47 \mathrm{~N} / \mathrm{mm}^{2} .
\end{aligned}
$$




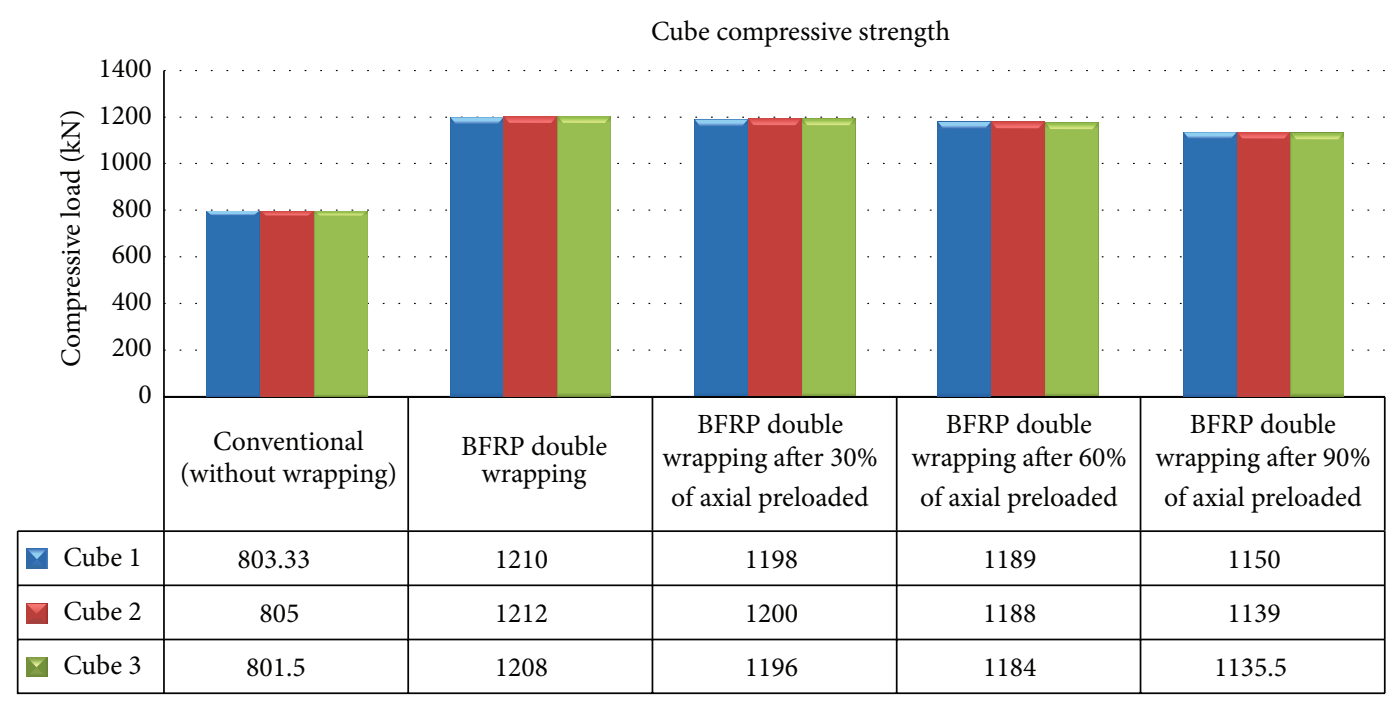

FIGURE 3: Conventional and BFRP retrofitted cubes performance compression load.



Figure 4: Retrofitting Constant $R_{c}$ Value for compressive strength.

BFRP double wrapped cube specimens preloaded by strength $90 \%$ of the compressive strength of conventional cube is calculated from constants as follows:

$$
f_{c k r}=f_{c k w R_{c}}
$$

or

$$
f_{c k r}=k_{1} f_{c k C_{c} R_{c}} .
$$

$R_{c}$ value is taken as 0.94 from graph shown in Figure 4. Consider

Ultimate stress of retrofitted specimens

$$
\begin{aligned}
& =1.19 \times 30 \times 1.5 \times 0.9 \\
& =50.33 \mathrm{~N} / \mathrm{mm}^{2} .
\end{aligned}
$$

3.3. Element Casting and Testing. The aim of this experiment is to test the retrofitting of damaged RCC end bearing piles using BFRP composites wrapping method. For this experiment the pile elements ultimate load carrying capacity

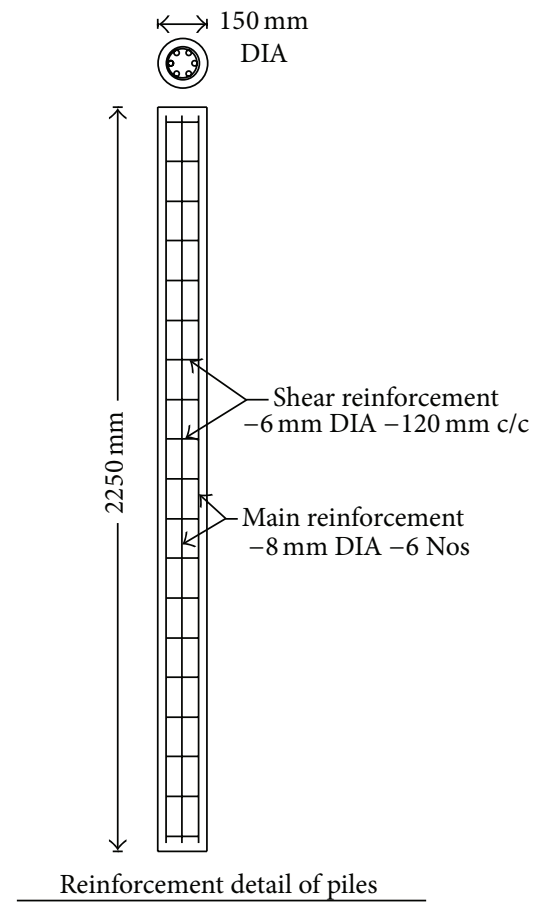

Figure 5: Reinforcement details of Pile elements.

of the pile elements $379 \mathrm{kN}$ was designed as per IS 4562000 and IS 2911-Part 1/Sec 3-1984. 15 pile elements were cast with uniform geometry, mechanical properties and reinforcements as shown in Table 9 and Figure 5 for testing purposes under different loading conditions as per Table 10 schedule.

The conventional pile elements (designated as AC 1, $\mathrm{AC} 2$, and $\mathrm{AC} 3$ ) were prepared for testing with following procedure. The pile elements were coated with white cement after cleaning of pile shaft; white cement wash is used for grids line marking and cracks pattern studies. Then the pile 

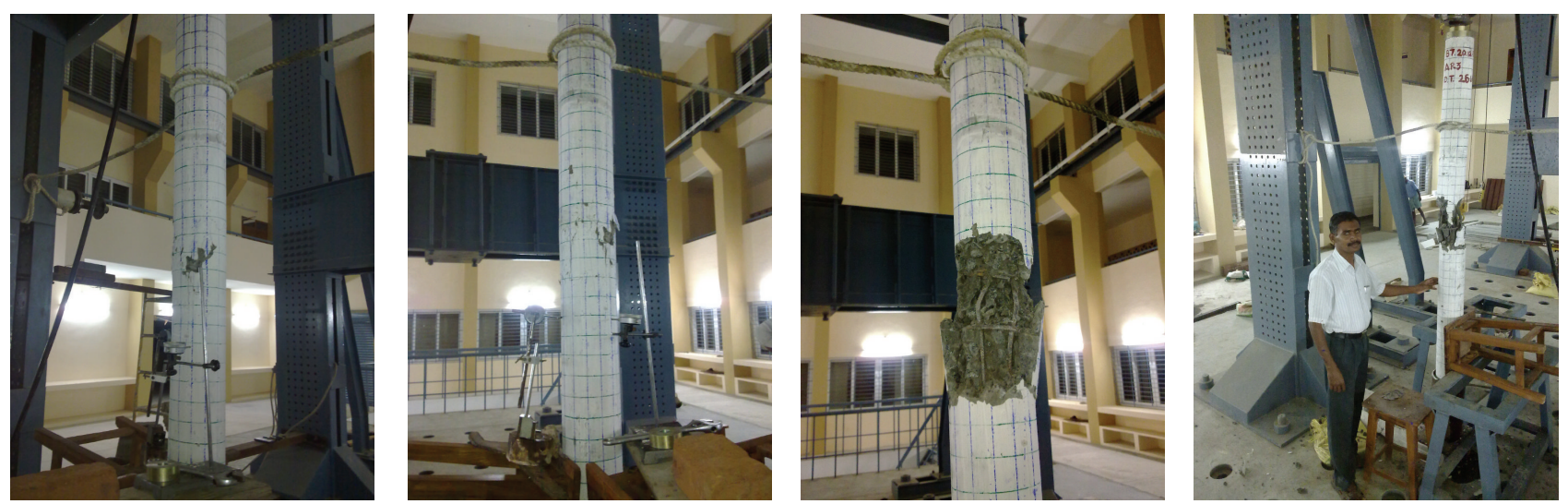

FIgURE 6: Conventional elements testing.

elements were fixed vertically in the $2000 \mathrm{kN}$ capacity loading frame. Besides, mechanical strain gauges were fixed at three places such as $1 / 3$ rd, middle, and $2 / 3$ rd spans interval for observing the deformation of elements during compressive loading. Two dial gauges were fixed at middle of elements on right side and back side for measuring the deflection of elements. Initial readings were observed during free loading condition. Then compressive load is applied at $50 \mathrm{kN}$ series interval up to ultimate carrying capacity of pile elements. For every $50 \mathrm{kN}$ loading intervals strain and dial gauge readings were observed and cracks formations places, patterns, width, and so forth were studied. The conventional pile elements fails at the middle due to compression as shown in Figure 6.

Similarly, the BFRP composites double wrapped elements were tested as per Table 10 schedule. In this, the orientation of fibre warp is made along the circumference; it is applicable for withstanding the hoop stress as the fibres won good tensile properties.

For retrofitting procedure, first the conventional pile elements were preloaded to $30 \%$ of ultimate compression load on three elements then double wrapped using BFRP composites. Similarly another 6 elements were preloaded to $60 \%$ and $90 \%$ on each 3 numbers before double wrapping with BFRP composites. Then elements were tested under the axial compressive loads.

The conventional pile elements were designed for an ultimate load carrying capacity of $379 \mathrm{kN}$. But, in this experiment the piles elements carried an ultimate mean load of $400 \mathrm{kN}$. The BFRP double wrapped elements withstand a mean ultimate load of $932 \mathrm{kN}$. The retrofitted elements preloaded to $30 \%, 60 \%$, and $90 \%$ withstand mean ultimate load of $922 \mathrm{kN}$, $912 \mathrm{kN}$, and $890 \mathrm{kN}$, respectively.

The deformation readings were observed from the mechanical strain gauge during the experiment for every $50 \mathrm{kN}$. From that reading the stress and strain values are found and plotted as shown in Figure 9.

\section{Results and Discussions}

In this experiment, the performance and behaviour of BFRP wrapped and retrofitted elements were observed under the
TABLE 7: BFRP wrapped concrete specimens characteristic stress.

\begin{tabular}{lcc}
\hline Specimens & $\begin{array}{c}\text { BFRP composites } \\
\text { wrapping layer }\end{array}$ & $\begin{array}{c}\text { Characteristics stress } \\
\text { in N/mm }\end{array}$ \\
\hline Cube & Single & 41.4 \\
& Double & 53.77 \\
\hline \multirow{2}{*}{ Cylinder } & Single & 6.25 \\
& Double & 8.18 \\
\hline \multirow{2}{*}{ Prisms } & Single & 11.05 \\
& Double & 12.08 \\
\hline
\end{tabular}

TABLE 8: Concrete specimens compressive stress comparison between experimental results and mathematical prediction.

\begin{tabular}{|c|c|c|}
\hline \multirow{2}{*}{$\begin{array}{l}\text { Description of concrete } \\
\text { cube specimens }\end{array}$} & \multicolumn{2}{|c|}{ Compressive stress in $\mathrm{N} / \mathrm{mm}^{2}$} \\
\hline & $\begin{array}{l}\text { Experimental } \\
\text { results }\end{array}$ & $\begin{array}{c}\text { Mathematical } \\
\text { prediction }\end{array}$ \\
\hline Conventional & 35.7 & 35.7 \\
\hline BFRP double wrapped & 53.77 & 53.77 \\
\hline $\begin{array}{l}30 \% \text { preloaded of ultimate } \\
\text { compressive load then } \\
\text { BFRP double wrapped }\end{array}$ & 53.50 & 53.22 \\
\hline $\begin{array}{l}60 \% \text { preloaded of ultimate } \\
\text { compressive load then } \\
\text { BFRP double wrapped }\end{array}$ & 52.75 & 52.47 \\
\hline $\begin{array}{l}90 \% \text { preloaded of ultimate } \\
\text { compressive load then } \\
\text { BFRP double wrapped }\end{array}$ & 50.75 & 50.33 \\
\hline
\end{tabular}

axial compressive load. The BFRP wrapped elements performed well in compression loading conditions by enhancing the load carrying capacity, resistance to deformation, and deflection than the conventional elements. Comparisons are as follow.

(1) From the initial test results shown in Tables 7 and 8 , it is clear that the BFRP double wrapped cube specimens possess $129 \%$ and $150 \%$ more axial compressive strength than single wrapping specimens and conventional specimens, respectively. Double BFRP 

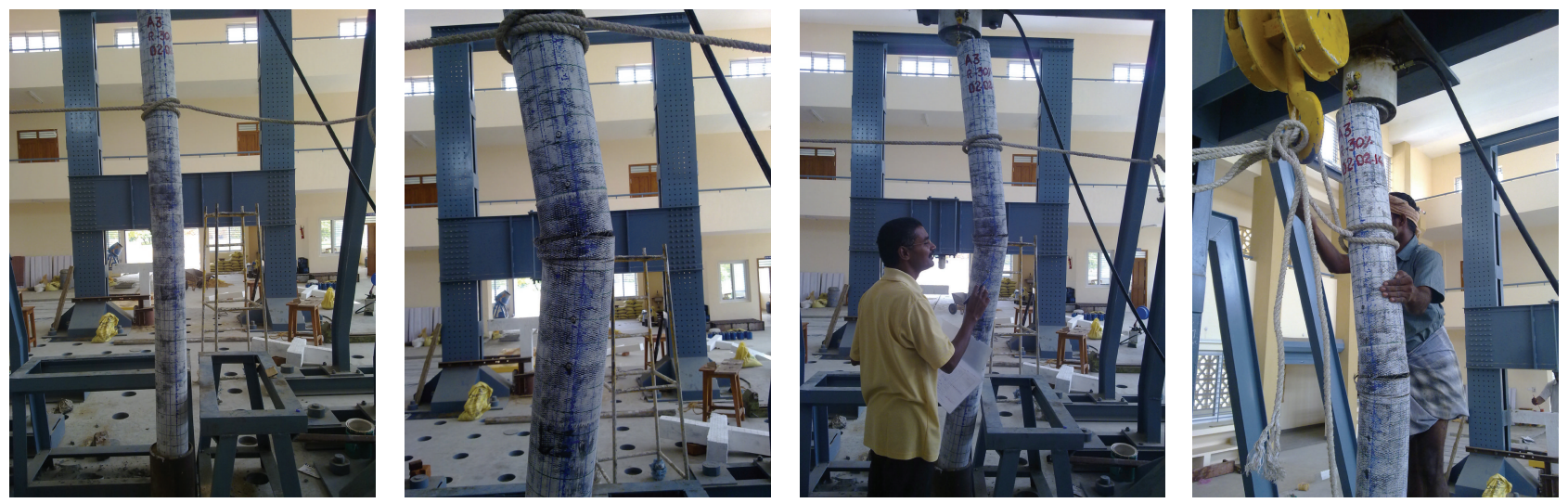

FIGURE 7: BFRP double wrapped elements testing.

TABLE 9: Properties of RCC end bearing piles.

\begin{tabular}{ll}
\hline $\begin{array}{l}\text { Diameter of pile } \\
\text { Height of pile }\end{array}$ & $\begin{array}{l}150 \mathrm{~mm} \\
2250 \mathrm{~mm}\end{array}$ \\
$\begin{array}{l}\text { Slenderness ratio } \\
\text { Main reinforcement }\end{array}$ & $\begin{array}{l}8 \mathrm{~mm} \varnothing \text { RTS rod-6 nos. } \\
\text { vertically } \\
6 \mathrm{~mm} \varnothing \text { RTS rod-120 mm c/c } \\
\text { spacing }\end{array}$ \\
Shear reinforcement & 1.706 \\
\% of reinforcement & M 30 \\
$\begin{array}{l}\text { Grade of concrete } \\
\text { BFRP wrapping thickness in } \\
\text { two layers }\end{array}$ & $2.04 \mathrm{~mm}$ \\
Basalt fibre orientation & $\begin{array}{l}\text { Warp comes along the } \\
\text { circumference direction }\end{array}$ \\
\hline
\end{tabular}

wrapped cylinders possess $130 \%$ and 206\% more split tensile strength than single wrapping specimens and conventional specimens, respectively. Similarly double BFRP wrapped prisms possess 109\% and 223\% more flexural strength than single wrapping specimens and conventional specimens, respectively. This is due to the unidirectional fabric wrapping which induces the strength of the specimens. Fibre warp made in the circumference withstands more hoop stress; thus, the BFRP wrapped specimens shows more strength.

(2) As shown in Figure 3 retrofitted specimens possess $149 \%, 147 \%$, and $142 \%$ more strength than conventional specimens. Generally fibres have good flexural and tensile strength than steel. Relative to that, the elements double wrapped with BFRP composites for retrofitting gives more compressive strength, high tensile strength and stiffness, leading to measure in load carrying capacity.

(3) In Figure 8, the load carrying capacity of pile elements were compared with conventional pile elements. The
BFRP wrapped elements attained 2.33 times more than conventional elements. Similarly, 30\%, 60\% and $90 \%$ preloaded then retrofitted pile elements showed enhancement in the compressive strength for about $2.3 \%, 2.27 \%$, and $2.25 \%$ times than conventional elements, respectively. This enhancement of compressive strength is caused by the wrapping of BFRP along the hoop direction which won good mechanical properties.

(4) The stress versus strain relation between BFRP wrapped and conventional pile elements was exposed in Figure 9. BFRP double wrapped elements remained stable than conventional elements during the axial compressive loading. In addition to that the volumetric strain was found to be lower than conventional elements. Thus, BFRP wrapping supports the elements to withstand and reduce its deformation under compressive loading.

(5) Cracks were initially formed at mid span of the conventional elements. First fine crack was formed at mid span on $225 \mathrm{kN}$ compressive loading. Thin cracks were formed at mid span and adjacent of the mid span on $250 \mathrm{kN}$. Medium cracks were formed at mid span and adjacent of the mid span on $300 \mathrm{kN}$. Medium cracks get widened on $350 \mathrm{kN}$. Width of the cracks increases abruptly on ultimate loading that is $400 \mathrm{kN}$ as shown in Figure 6. BFRP composites wrapped piles get buckled and torn at ultimate loading as shown in Figure 7.

(6) Strength of Retrofitted specimens were found using mathematical prediction and compared with experimental results as shown in Table 8. The mathematical prediction results show negligible deviations with experimental results.

(7) The load carrying capacity of conventional pile specimens and retrofitted pile specimens were compared as per IS 2911-Part 1/Sec 3-1984. 
TABLE 10: Schedule of RCC pile elements testing program.

\begin{tabular}{llcc}
\hline Sl. No. & Description of element & Designation of element & Nos. element used for testing \\
\hline 1 & $\begin{array}{l}\text { Conventional element } \\
\text { BFRP composites double wrapped element }\end{array}$ & AC 1, AC 2, and AC3 & 3 \\
3 & $\begin{array}{l}\text { 30\% preloaded of conventional element } \\
\text { ultimate load the BFRP double wrapped }\end{array}$ & AR3-1, AR3-2, and AR3-3 & 3 \\
4 & $\begin{array}{l}60 \% \text { preloaded of conventional element } \\
\text { ultimate load the BFRP double wrapped } \\
90 \% \text { preloaded of conventional element } \\
\text { ultimate load the BFRP double wrapped }\end{array}$ & AR6-1, AR6-2, and AR6-3 \\
& & AR9-1, AR9-2, and AR9-3 & 3 \\
\hline
\end{tabular}

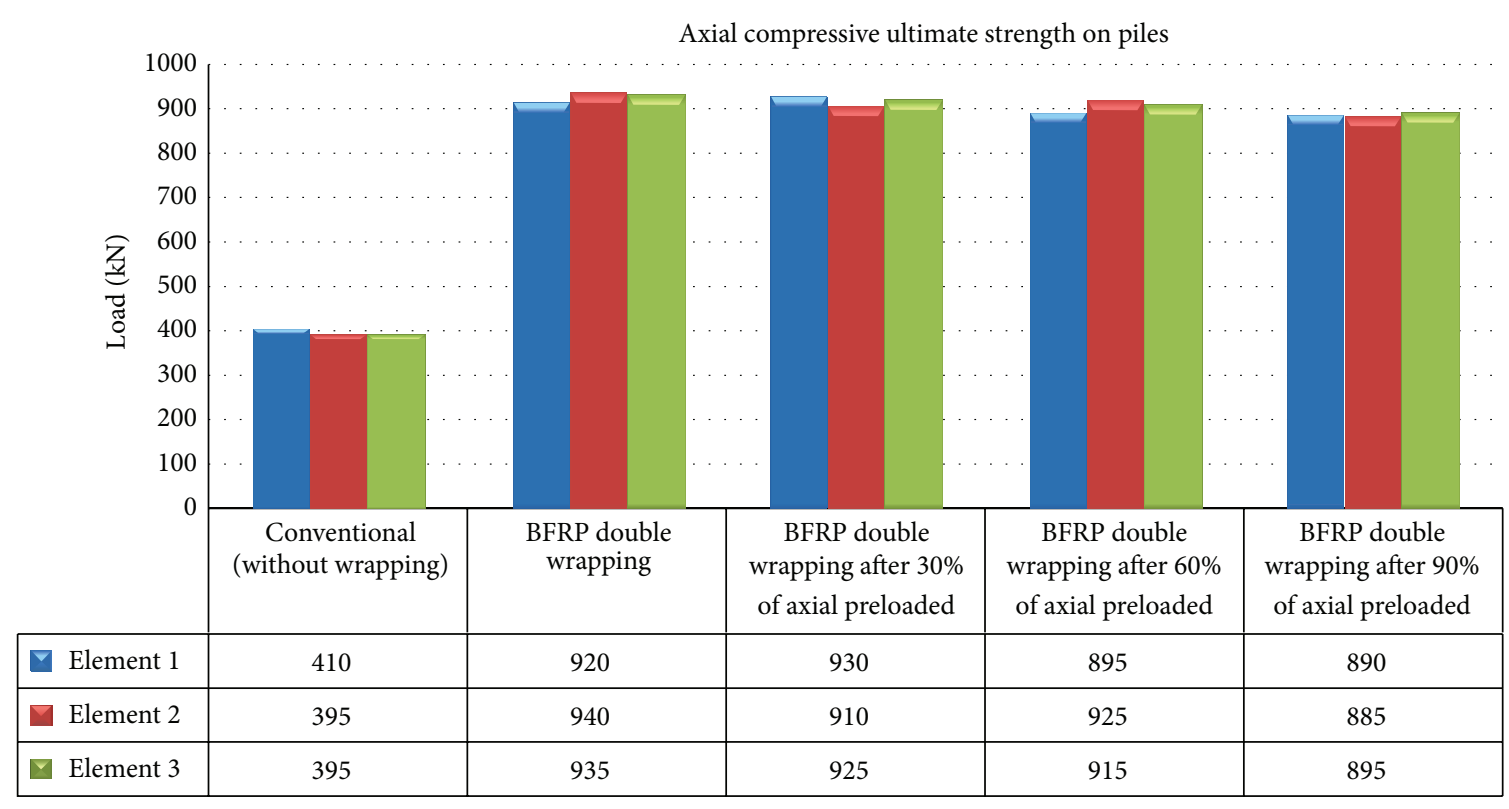

FIGURE 8: Experimental results of RCC pile elements under the compression.

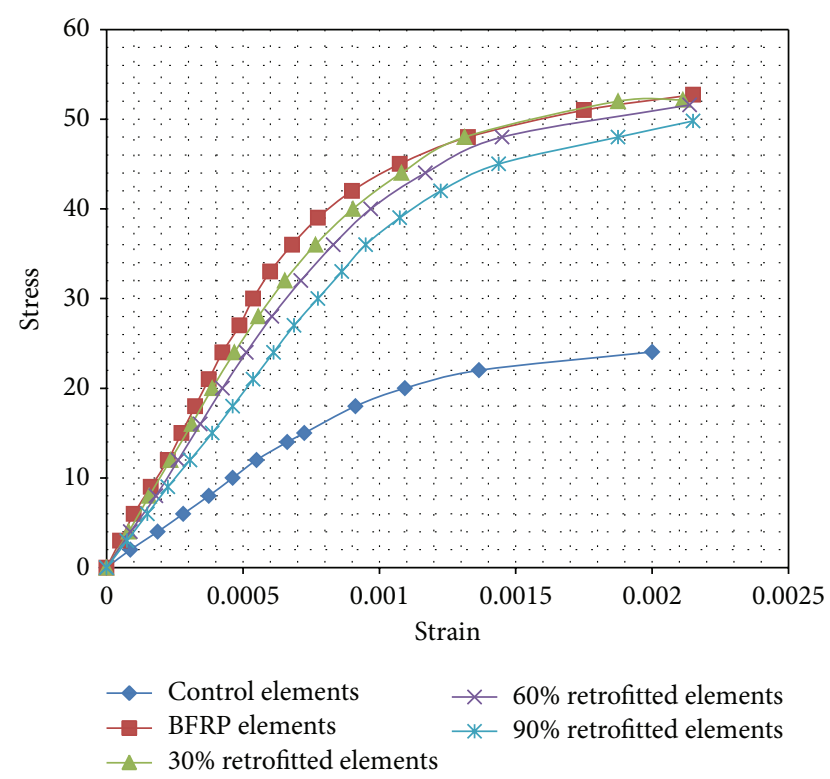

FIgure 9: Stress versus Strain Curve for axial compression loaded pile elements.

\section{Conclusion}

From the research results it is concluded that BFRP wrapped pile elements withstand more load carrying capacity, resistance to deformation, and deflection than the conventional elements.

The BFRP double wrapped cube specimens carried more axial compressive strength than single wrapped specimens and conventional specimens. Similarly double wrapped prisms and cylinders were more load carrying capacity than single wrapped and conventional specimens.

The double wrapped element with BFRP composites for retrofitting gives more compressive strength, high tensile strength, and stiffness.

Retrofitted piles after $30 \%, 60 \%$, and $90 \%$ preloaded pile elements showed more enhancement in compressive strength than conventional elements. The enhancement of compressive strength is due to the wrapping of BFRP in the hoop direction.

BFRP double wrapped elements remained more stabled than the conventional elements during the axial loading. The volumetric strain is lower than conventional elements. 
The formation of the crack and the crack width on BFRP wrapped pile elements was at very high load ranges when compared to the conventional elements.

Further research can be done to determine the various types of the loading such as lateral load, impact load, and so forth with varying the slenderness ratio. The further works can be extended for finding out the values of durability aspects. This research can be extend for finding out the load carrying capacity of the various types of piles like friction pile, friction, and end bearing pile.

Retrofitting of piles with BFRP wrapping results in tremendous increase of strength parameters and performance of piles. BFRP wrapping endures corrosion and increase the life of the elements. Thus, it can be concluded that BFRP wrapping can be used for retrofitting of members where compression prevails.

\section{Conflict of Interests}

The authors declare that there is no conflict of interests regarding the publication of this paper.

\section{References}

[1] B. Purushotham Reddy, P. Alagusundaramoorthy, and R. Sundaravadivelu, "Retrofitting of RC piles using GFRP composites," KSCE Journal of Civil Engineering, vol. 13, no. 1, pp. 39-47, 2009.

[2] K. Olivova and J. Bilcik, "Strengthening of concrete columns with CFRP," Slovak Journal of Civil engineering, vol. 17, no. 1, pp. $1-9,2009$.

[3] R. Abbasnia and A. Holakoo, "An investigation of stress-strain behavior of FRP-confined concrete under cyclic compressive loading," International Journal of Civil Engineering, vol. 10, no. 3, pp. 201-209, 2012.

[4] T. Yu, Y.-B. Cao, B. Zhang, and J. G. Teng, "Hybrid FRP-concrete-steel double-skin tubular columns: cyclic axial compression tests," Research Online, 6th International Conference on FRP Composites in Civil Engineering, pp. 1-8, 2012.

[5] C. Desprez and P. J. Mazars, "Stress-strain model for FRP confined concrete columns under cyclic and seismic loading," in Proceedings of the 15th World Conference on Earthquake Engineering (WCEE '12), Lisbon, Portugal, 2012, http://www.iitk .ac.in.

[6] T. Ozbakkaloglu and B. A. Louk Fanggi, "FRP-HSC-steel composite columns: behavior under monotonic and cyclic axial compression," Materials and Structures, pp. 1-19, 2013.

[7] B. Ferracuti and M. Savoia, "Cyclic behaviour of FRP-wrapped columns under axial and flexural loadings," in Proceedings of the International Conference on Fracture, Turin, Italy, 2005.

[8] R. Sadone, M. Quiertant, J. Mercier, and E. Ferrier, "Experimental study on RC columns retrofitted by FRP and subjected to seismic loading," in Proceedings of the 6th International Conference on FRP Composites in Civil Engineering (CICE '12), Rome, Italy, 2012, http://www.iifc-hq.org.

[9] A. Mirmiran, Y. Shao, and M. Shahawy, "Analysis and field tests on the performance of composite tubes under pile driving impact," Composite Structures, vol. 55, no. 2, pp. 127-135, 2002.

[10] A. Fam, M. Pando, G. Filz, and S. Rizkalla, "Precast piles for route 40 bridge in Virginia using concrete filled FRP tubes," PCI Journal, vol. 48, no. 3, pp. 32-45, 2003.
[11] A. Parvin and D. Brighton, "FRP composites strengthening of concrete columns under various loading conditions," Polymers, vol. 6, no. 4, pp. 1040-1056, 2014. 

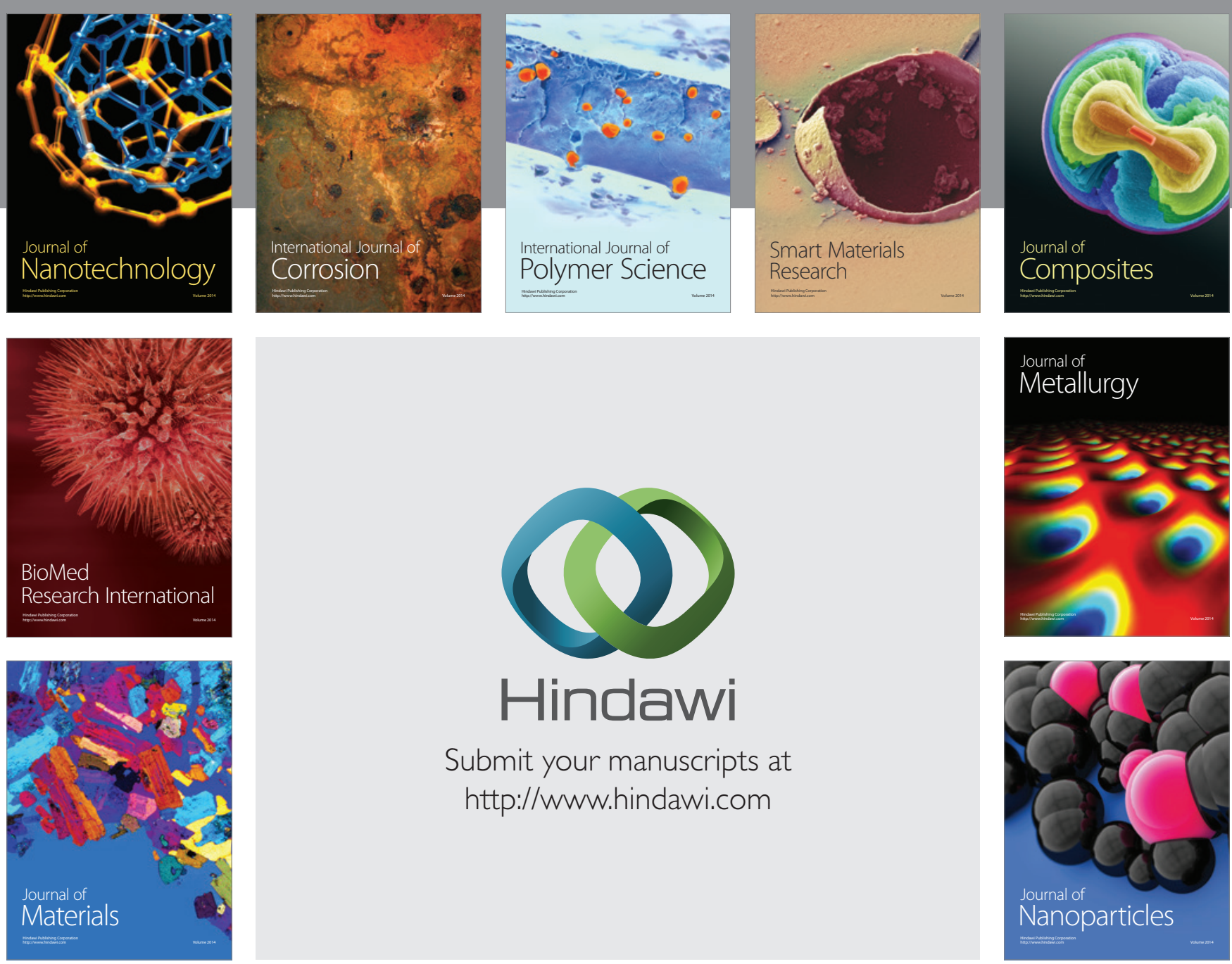

Submit your manuscripts at http://www.hindawi.com


\section{The Scientific World Journal}
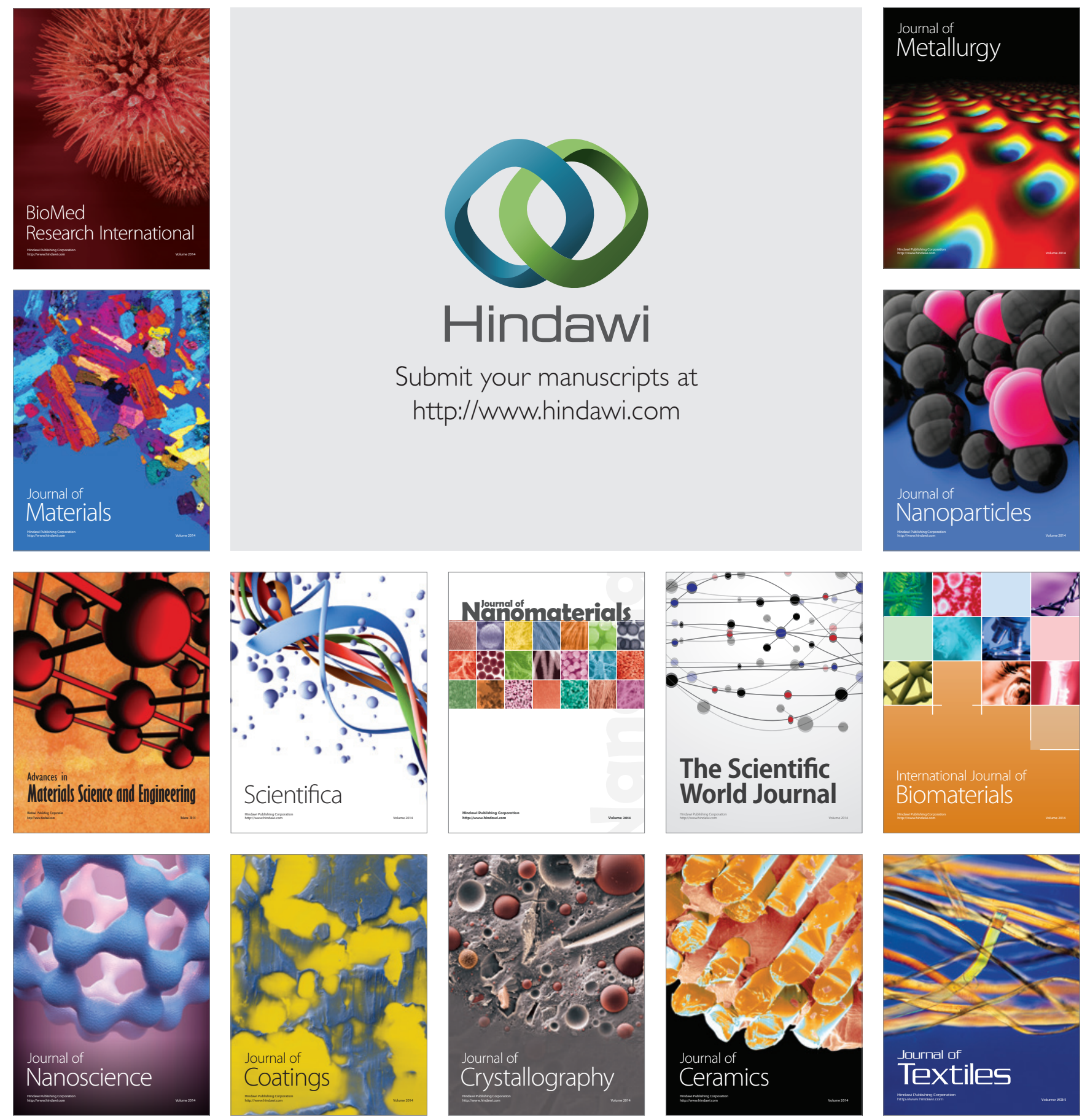